\title{
FLEXIBILIDAD CONSTITUCIONAL Y DEMOCRACIA: UNA REVISIÓN CRÍTICA A LA TEORÍA LIBERAL. EXPLORANDO LA EXPERIENCIA DE URUGUAY, VENEZUELA Y CHILE \\ Constitutional flexibility and democracy: A critical review of liberal theory. Exploring the experience of Uruguay, Venezuela and Chile
}

\author{
RODRIGO ESPINOZA TRONCOSO \\ Universidad Diego Portales \\ rodrigo.espinoza_t@mail.udp.cl
}

Cómo citar/Citation

Espinoza Troncoso, R. (2021).

Flexibilidad constitucional y democracia: una revisión crítica a la teoría liberal.

Explorando la experiencia de Uruguay, Venezuela y Chile.

Revista de Estudios Políticos, 191, 215-245.

doi: https://doi.org/10.18042/cepc/rep.191.08

\section{Resumen}

El artículo discute sobre la relación entre rigidez constitucional y democracia. De acuerdo al liberalismo, constituciones más flexibles (o menos rígidas) producen democracias más débiles. Con el propósito de probar que esta relación no se cumple en todos los casos, la investigación examina el caso de Uruguay como un caso atípico de baja rigidez constitucional, democracia estable y reformas que no han debilitado la democracia electoral. Por otro lado, se argumenta sobre las desventajas en la implementación de elevadas barreras de enmienda explorando dos casos: Venezuela bajo la Constitución de 1961 y Chile bajo la Constitución de 1980. El análisis de los casos ilustra que constituciones más flexibles no necesariamente producen democracias más débiles o reformas que debiliten la democracia. Asimismo, elevados niveles de rigidez pueden generar problemas de adaptación de los sistemas constitucionales a las demandas de su entorno. 


\section{Palabras clave}

Rigidez constitucional; democracia; Uruguay; Venezuela; Chile.

\section{Abstract}

The article discusses about the relation between constitutional rigidity and democracy. According to liberal theory, flexible constitutions (or decreasing levels of constitutional rigidity) produces weak democracies. In order to asses that this relation is not aplicable for every case, the research explores the case of Uruguay as an exceptional case: low levels of contitutional rigidity; stable democracy and inexistance of reforms that erodes democracy. Also, the paper discusses about the flaws of stringent amendment rules, exploring two cases: Venezuela under 1961 constitution and Chile under the rule of 1980 constitution. The case análisis shows that flexible constitutions not necesarilly leads to weak democracies. On the other hand, the potential problem of stringent amendment rules is the lack of response to the demands from the environment.

\section{Keywords}

Constitutional rigidity; democracy; Uruguay; Venezuela; Chile. 


\section{SUMARIO}

I. INTRODUCCIÓN. II. ASPECTOS TEÓRICOS. III. ASPECTOS METODOLÓGICOS. IV. URUGUAY: UN CASO EXCEPCIONAL QUE ESCAPA A LOS SUPUESTOS DEL LIBERALISMO: 1. Reglas de enmienda de la Constitución uruguaya. 2. Principales reformas constitucionales. 3. Participación ciudadana en el diseño de reformas. V. ALGUNOS ALCANCES SOBRE LA RIGIDEZ CONSTITUCIONAL EXTREMA: 1. Venezuela. 2. Chile. VI. CONCLUSIONES. BIBLOGRAFía.

\section{INTRODUCCIÓN}

Una de las principales propuestas teóricas del constitucionalismo liberal está vinculada a la relación entre rigidez constitucional y democracia. De acuerdo al liberalismo, mayores niveles de rigidez constitucional (o barreras a los procesos de enmienda a la constitución) tienen un impacto positivo sobre la democracia debido a que prevendría cambios bruscos a las reglas del juego democrático, sumado a que protegería a las minorías frente a potenciales cambios por parte de mayorías circunstanciales. Asimismo, mayores niveles de rigidez fortalecerían el nivel de consenso político, dado que umbrales supramayoritarios incentivarían acuerdos políticos más amplios. En síntesis, estos elementos prevendrían lo que se denomina como la tiranía de la mayoría, evitando cambios destinados a debilitar al sistema democrático.

Siguiendo los planteamientos del liberalismo, se podría asumir que constituciones más flexibles o con reglas de enmiendas más permisivas producirían como resultado democracias más débiles en contraste con aquellas que poseen mayores niveles de rigidez, debido a la presencia constante de cambios radicales a las reglas del juego sin considerar la voluntad de las minorías. La presente investigación pretende ir en la dirección contraria, argumentando que constituciones con menores grados de rigidez no necesariamente conducen al debilitamiento de la democracia.

Para confirmar el argumento se explorará el caso de Uruguay desde el retorno a la democracia (1985). Uruguay se rige bajo la Constitución de 1966, caracterizada por sus reducidas barreras para su reforma. Pese a esta menor rigidez, Uruguay es uno de los países con mayores niveles de democracia en América Latina. A pesar de sus reducidos requisitos para la reforma, la Constitución de 1966 tan solo se ha reformado en cuatro oportunidades desde el retorno a la democracia $(1989,1994,1996$ y 2004), incluyendo dos reformas 
mediante iniciativa ciudadana, lo que ha incentivado la participación de la ciudadanía en conjunto con los partidos políticos en el diseńo de reformas constitucionales. Los elementos descritos convierten a Uruguay en un caso excepcional que se aleja de los supuestos teóricos del liberalismo.

A modo complementario, también se harán algunos alcances sobre los potenciales problemas que pudiera arrojar elevados niveles de rigidez explorando dos casos: Venezuela bajo la Constitución de 1961 y Chile bajo la Constitución de 1980. Se argumenta que una elevada rigidez constitucional no necesariamente asegura la estabilidad del sistema democrático, ya que el principal problema de este tipo de constituciones sería la falta de adecuación o adaptación a las demandas de su entorno.

La investigación está compuesta por cinco secciones. En la primera se abordarán los aspectos teóricos. Posteriormente se explorarán los aspectos metodológicos. En la tercera sección se abordará el análisis del caso uruguayo, mientras que durante la cuarta parte se discutirán algunos alcances sobre reglas de enmienda extremadamente rígidas. La quinta parte y final corresponde a las conclusiones.

\section{ASPECTOS TEÓRICOS}

Parte importante de todo sistema democrático radica en el conjunto de reglas que permiten alterar las reglas del juego. Este punto no deja de ser menor, debido a que la enmienda constitucional es un mecanismo de adaptación que posee toda constitución ante las demandas de su entorno. Sobre todo si consideramos que los procesos de cambio constitucional son convulsionados, lo que hace aflorar elementos tales como la incertidumbre, racionalidad, pasión y egoísmo por parte de los actores (Elster, 1995). Bajo estas condiciones, las constituciones no pueden considerarse como objetos libres de imperfecciones ni como estructuras pétreas (Levinson 1995), sino más bien que requieren de adaptación para una mayor longevidad (Elkins et al., 2009; Negretto 2012), dado que pueden volverse obsoletas o, dicho de otro modo, en instrumentos que no permiten proveer a la ciudadanía los bienes públicos que esta demanda.

En términos comparados, cada constitución tiene sus propias reglas para ser reformada. Asimismo, cada sistema constitucional, en virtud de la cantidad de obstáculos que posee para su modificación, refleja la voluntad de otorgar o no un estatus distinto a la constitución, estando habitualmente por encima de la legislación ordinaria. Es en este punto donde entran dos visiones opuestas: rigidez y flexibilidad constitucional.

De acuerdo a Bryce (1952), las constituciones de carácter rígido poseen reglas más exigentes que la legislación ordinaria para su modificación parcial, 
debido a que la intención está en otorgar a la carta fundamental un estatus superior en comparación al resto de leyes. Por otro lado, se entiende como flexible a todo ordenamiento jurídico que no diferencia entre el procedimiento para la enmienda constitucional y la legislación ordinaria. Vale decir: las barreras de aprobación son similares.

El debate vinculado a la formula óptima para reformar un sistema constitucional se remonta a los debates previos a la instauración de la Constitución de los Estados Unidos. Dentro de dicho contexto, Madison defendió la instauración de una constitución rígida, que sea capaz de prevenir cambios radicales a fin de tener un sistema de reglas estables que se prolongue a lo largo del tiempo y que proteja el derecho a propiedad ante el comportamiento pasional de las mayorías (Closa, 2012; Hamilton et al., 2006). Contrario a la postura liberal, Jefferson promovió el derecho de cada generación a regirse bajo la forma que estime más adecuada, argumentando que la durabilidad de una constitución no debiese ser superior a los veinte años (Closa, 2012; Elkins et al., 2009).

Dentro de la literatura contemporánea se ha señalado que mayores niveles de rigidez constitucional tendrían un impacto positivo sobre las democracias debido a que, tal y como sostuvo Madison, se prevendría la «tiranía de la mayoría", otorgándose poder de veto a las minorías con el objeto de frenar reformas radicales por parte de mayorías circunstanciales cuyo propósito sería mantenerse y concentrar el poder de forma indefinida, lesionando las bases sostenedoras del sistema democrático (Buchanan y Tullock, 1962; Dixon y Landau, 2015; Landau, 2013).

Por otra parte, la literatura también ha sostenido que mientras mayores son los niveles de rigidez de una constitución, se fortalecería el modelo de democracia consensual (Lijphart, 1999). Esta relación se daría principalmente por la existencia de reglas de votación supramayoritarias como requisito de aprobación en el debate legislativo. En estricto rigor, esto incentivaría a las mayorías que tengan una posición reformista a buscar el apoyo de sus adversarios electorales, conduciendo a pactos políticos prácticamente transversales en el seno de las instituciones representativas. Esto se vería doblemente reforzado si se toma en consideración la existencia de bicameralismo. También se puede añadir la presencia de un tercer factor: el otorgamiento de la última palabra al sistema judicial o a la justicia constitucional (Schwartzberg, 2010). Por lo tanto, estos constreñimientos, además de promover el consenso, conducirían a cambios moderados en las reglas del juego que rigen a todo sistema democrático, neutralizando posturas radicales. Por esta razón es que se considera que el incremento en los niveles de rigidez constitucional actúa como una suerte de sello que protege las bases fundamentales de la democracia.

En función de lo sostenido por el liberalismo, reducidos niveles de rigidez conducirían a democracias más débiles. No obstante, ¿̇se cumple esta premisa 
en todos los casos? Para ello se analizará el caso de Uruguay como un caso excepcional, dado que posee reglas de enmienda relativamente permisivas junto a altos niveles de democracia electoral y un correcto funcionamiento del sistema de frenos y contrapesos, elementos que serán discutidos en la sección destinada a los aspectos metodológicos. En conjunto, también se harán algunos alcances sobre los problemas que pueden tener constituciones con niveles de rigidez extremadamente altos.

\section{ASPECTOS METODOLÓGICOS}

El propósito de la investigación consiste verificar si constituciones con reglas de enmienda más flexibles necesariamente producen democracias más débiles. Con el afán de comprobar que esta premisa no se cumple en todos los casos, se estudiará en profundidad el caso de Uruguay tras el retorno a la democracia (1985) bajo el alero de la Constitución de 1966.

Repasando las reglas de enmienda, la Constitución de Uruguay posee reducidos niveles de rigidez. De acuerdo con lo establecido en el art. 331, pueden presentar proyectos de reforma tanto el poder legislativo, ejecutivo y la ciudadanía. En el caso de la Asamblea Nacional, solo se requiere el apoyo dos quintas partes para luego ser votado en el referendo. Mientras tanto, la ciudadanía solo necesita el $10 \%$ de las firmas del padrón electoral para luego ser votadas en referendo sin necesidad de superar quórums legislativos. En ambos casos, para que la iniciativa sea aprobada se requiere la mayoría de los votos en la fase referendo (aunque los caminos para la reforma serán revisados en mayor detalle en la siguiente sección). Esta mayor flexibilidad, si se toman como correctos los supuestos del liberalismo, llevaría a dos tipos de problemas: a) democracia débil y b) cambios frecuentes y radicales en la constitución.

Tabla 1. Funcionamiento componentes electoral, liberal y participativo en América Latina (2019)

\begin{tabular}{lccc}
\hline País & $\begin{array}{c}\text { Componente } \\
\text { electoral }^{*}\end{array}$ & $\begin{array}{c}\text { Componente } \\
\text { liberal }^{* *}\end{array}$ & $\begin{array}{c}\text { Componente } \\
\text { participativo*** }^{* *}\end{array}$ \\
\hline Argentina & 0,87 & 0,74 & 0,58 \\
\hline Bolivia & 0,64 & 0,48 & 0,68 \\
\hline Brasil & 0,80 & 0,73 & 0,57 \\
\hline Chile & 0,86 & 0,91 & 0,61 \\
\hline
\end{tabular}




\begin{tabular}{lccc}
\hline País & $\begin{array}{c}\text { Componente } \\
\text { electoral }^{*}\end{array}$ & $\begin{array}{c}\text { Componente } \\
\text { liberal }\end{array}$ & $\begin{array}{c}\text { Componente } \\
\text { participativo*** }^{* *}\end{array}$ \\
\hline Colombia & 0,84 & 0,72 & 0,63 \\
\hline Costa Rica & 0,93 & 0,92 & 0,65 \\
\hline Ecuador & 0,75 & 0,70 & 0,66 \\
\hline El Salvador & 0,71 & $0,68^{* * * *}$ & 0,53 \\
\hline Guatemala & 0,70 & 0,58 & 0,57 \\
\hline Honduras & 0,44 & 0,41 & 0,54 \\
\hline México & 0,80 & 0,65 & 0,53 \\
\hline Nicaragua & 0,35 & 0,10 & 0,43 \\
\hline Panamá & 0,86 & 0,72 & 0,58 \\
\hline Paraguay & 0,70 & 0,66 & 0,59 \\
\hline Perú & 0,84 & 0,86 & 0,65 \\
\hline República Dominicana & 0,67 & 0,45 & 0,58 \\
\hline Uruguay & 0,88 & 0,91 & 0,80 \\
\hline Venezuela & 0,34 & 0,20 & 0,43 \\
\hline
\end{tabular}

* Extensión del sufragio, grado de libertad con que opera la sociedad civil y elecciones limpias.

** Funcionamiento del sistema de frenos y contrapesos.

*** Participación de la ciudadanía en procesos electorales y no electorales.

**** Año 2019 no disponible, por lo que se usaron los datos correspondientes a 2018.

Fuente: Varieties of Democracy ${ }^{1}$.

La tabla 1 muestra que Uruguay es uno de los países con mayores niveles en lo que se refiere al funcionamiento del componente electoral de democracia $(0,88)$, siendo solo superado por Costa Rica $(0,91)$. Observando el componente liberal que mide el funcionamiento del sistema de checks and balances, Costa Rica $(0,92)$, Uruguay $(0,91)$ y Chile $(0,91$ y 0,86 en el componente electoral) presentan los valores más elevados a nivel regional. Si se comparan las reglas de enmienda de estos tres países, tanto Costa Rica como Chile son países que poseen altos niveles de rigidez constitucional.

1 La medición realizada por V-DEM para cada uno de los componentes va desde 0 a 1 de forma continua. Entre más cercano a 1 mejor es el funcionamiento de cada uno de los componentes reflejados en la tabla. 
En el caso de la Constitución de Costa Rica (art. 195), pueden presentar reformas el poder legislativo y la ciudadanía mediante el 5\% de las firmas del padrón electoral. Para ser aprobado, en ambos casos se requiere de la aprobación de la Asamblea por votación de dos tercios del total de sus miembros para luego conformarse una comisión que deberá aprobar la reforma por mayoría absoluta y luego pasar a manos del Ejecutivo. El Ejecutivo, una vez recibido el proyecto, deberá enviarlo nuevamente a la Asamblea Legislativa en la próxima legislatura ordinaria con sus observaciones. Finalmente, la reforma formará parte de la Constitución si se vuelve a aprobar por dos terceras partes de los miembros de la Asamblea.

En Chile el proceso de enmienda no deja de ser exigente (art. 127). Solo pueden presentar proyectos de reforma el Ejecutivo y el Congreso. La ciudadanía no está facultada para presentar reformas. En caso de ser aprobadas, esta requiere el apoyo de tres quintas partes de los miembros en ejercicio tanto de la Cámara de Diputados como del Senado. No obstante, existen capítulos de la Constitución que requieren del apoyo de dos terceras partes en ambas cámaras. Estos capítulos están asociados a las bases de la institucionalidad, derechos y deberes constitucionales, el Tribunal Constitucional, Fuerzas Armadas, el Consejo de Seguridad Nacional y las reglas para la reforma (capítulos I, III, VIII, XI, XII y XV).

Como se puede apreciar, comparativamente Uruguay tiene una democracia electoral sólida y un correcto funcionamiento del sistema de controles horizontales pese a tener una Constitución más flexible en comparación con Costa Rica y Chile, que presentan números similares, pero con reglas de enmienda más restrictivas. Lo que observamos entonces es que Uruguay es un caso atípico, con resultados que se distancian de los argumentos teóricos sostenidos por el liberalismo.

Otro elemento para resaltar son las cifras asociadas al componente participativo. En lo que a este índice se refiere, Uruguay presenta las cifras más altas de la región $(0,80$, seguido por Bolivia con 0,68$)$ y muy por encima de Costa Rica $(0,65)$, Chile $(0,61)$ y el resto de los países presentados en la tabla 1 . Como se verá en la siguiente sección, la Constitución uruguaya de 1966 no solo consolida una larga tradición en el uso de mecanismos de democracia directa, sino que, además, sus menores niveles de rigidez constitucional han permitido la inclusión de la ciudadanía en el diseño de reformas constitucionales, siendo las reformas de 1989 y de 2004 (última reforma constitucional) introducidas mediante el mecanismo de iniciativa ciudadana.

Otro elemento que convierte al caso uruguayo como excepcional es su reducida cantidad de reformas, la que ha sido sometida a cambios en cuatro oportunidades. 
Tabla 2. Año en que la constitución ha sido sometida a reformas tras el retorno a la democracia

\begin{tabular}{|c|c|}
\hline País & Año \\
\hline Chile & $\begin{array}{c}1991,1994,1996,1997,1998,1999,2000,2001,2003, \\
2005,2007,2008,2009,2011,2012,2013,2014,2015, \\
2016,2017,2018,2019\end{array}$ \\
\hline Costa Rica & $\begin{array}{c}\text { 1954, 1956, 1957, 1958, 1959, 1961, 1963, 1965, 1968, } \\
1969,1971,1972,1973,1975,1977,1981,1982,1984, \\
1987,1989,1991,1993,1994,1995,1996,1997.1999, \\
2000,2001,2002,2003,2011,2015,2018,2019\end{array}$ \\
\hline Uruguay & 1989, 1994, 1996, 2004 \\
\hline
\end{tabular}

Fuente: Comparative Constitutions Project.

De acuerdo a los datos de la tabla 2, Uruguay, pese a tener una Constitución con reducidos umbrales para su reforma, esta ha sufrido modificaciones con menor frecuencia tras el retorno a la democracia (1985) si se compara con Costa Rica (transición en 1954) y Chile (transición en 1990), países que han sometido sus constituciones a reforma con relativa frecuencia.

En consecuencia, la selección de Uruguay como estudio de caso se justifica por ser un ejemplo atípico que se desvía de los fundamentos de la teoría constitucional liberal: a) posee elevados niveles en cuanto al funcionamiento del componente electoral de democracia; b) un correcto funcionamiento del sistema de frenos y contrapesos; c) baja frecuencia en el número de enmiendas, y d) elevados niveles en cuanto a participación de la ciudadanía, tanto en procesos electorales como no electorales si se compara con el resto de la región.

La selección metodológica basada en el estudio de caso se justifica principalmente porque permite explorar de mejor manera casos atípicos, contrario a un enfoque cuantitativo donde los casos que se escapan a la teoría solo son considerados como observaciones que afecta a la variabilidad de los datos y constituyen una parte del error estadístico (King et al., 1994). Otra de sus fortalezas es que permite observar en detalle el comportamiento de relaciones causales mediante el estudio de acontecimientos basados en un orden cronológico-secuencial, aunque sus limitaciones están en la validez externa a pesar de que la utilidad del estudio de un caso en profundidad también radica en que permite someter a testeo, revisión y reconstrucción a una teoría (Goertz y Mahoney, 2012).

Finalmente, es importante señalar que por democracia se utilizará la definición otorgada por Dahl (1971). Por ende, un país será democrático si reúne las siguientes las siguientes condiciones: a) elecciones periódicas, libres, 
competitivas y transparentes; b) libertad de expresión y asociación, c) existencia de sufragio universal.

\section{URUGUAY: UN CASO EXCEPCIONAL QUE ESCAPA A LOS SUPUESTOS DEL LIBERALISMO}

La actual Constitución política de Uruguay se creó en 1966 como resultado de un cúmulo de esfuerzos históricos por avanzar hacia el modelo suizo de democracia por medio de la incorporación de diversos mecanismos de democracia directa (Altman, 2008; González, 2008). El documento se promulgó justo en medio de una crisis política y económica que culminó con el quiebre democrático de 1973. Sin embargo, la Constitución se reestableció en 1985 junto con la transición a la democracia.

Una de las características fundamentales de la Constitución uruguaya es su reducido nivel de rigidez. Sin embargo, contrario a lo que propone el constitucionalismo liberal, la menor rigidez de la carta de 1966 no ha derivado en un sistema democrático débil, sino todo lo contrario. El país es una de las democracias más estables de América Latina, sumado a que posee los mayores índices regionales en cuanto al funcionamiento del componente participativo. Esto último está muy asociado a las reglas de enmienda existentes, ya que ha permitido la vinculación entre partidos políticos, especialmente el Frente Amplio (FA), y la ciudadanía. Este último actor ha presentado múltiples iniciativas de reforma constitucional que han sido aprobadas (1989 y 2004). Por otro lado, las reformas realizadas no han implicado un uso abusivo del poder ${ }^{2}$.

La siguiente sección se divide en tres partes. En la primera se explorarán las reglas de enmienda de la Constitución de 1966. Durante la segunda se abordarán las reformas realizadas desde el retorno a la democracia, mientras que la tercera parte estudiará la participación de la ciudadanía en el diseño de reformas a la Constitución.

\section{REGLAS DE ENMIENDA DE LA CONSTITUCIÓN URUGUAYA}

El art. 331 establece la manera en que el texto puede ser modificado. Respecto al poder de iniciativa, se encuentran facultados el presidente de la república, la Asamblea General y la ciudadanía.

2 Podría citarse como ejemplo de abuso la reforma de 1996, que tuvo como propósito impedir la llegada del Frente Amplio al Gobierno. Sin embargo, como se verá posteriormente, la reforma no implicó un deterioro de la democracia, sumado a que el Frente logra llegar a la Presidencia en el año 2004. 
En el caso del Ejecutivo, para realizar modificaciones a la Constitución requiere la aprobación de la mayoría absoluta del total de miembros de la Asamblea General y posterior aprobación mediante referendo. El poder legislativo puede enviar a referendo una iniciativa para la reforma constitucional con el apoyo de dos quintos de sus miembros. Finalmente, la ciudadanía, reuniendo el $10 \%$ de las firmas del padrón electoral, puede someter a referendo una propuesta de reforma. Cabe destacar que en todos los casos para que sea aprobado el referendo se requiere de la mayoría de los votos emitidos, sumado a un umbral de participación electoral de al menos un $35 \%$.

Por consiguiente, solo el Ejecutivo debe pasar por la Asamblea General antes de someter la iniciativa a referendo. La iniciativa ciudadana pasa directamente a referendo tras reunir las firmas requeridas. El poder legislativo con el apoyo de dos quintos de sus miembros puede pasar directo a referendo. En el caso de este último actor, existen otros procedimientos que requieren mayoría absoluta en la Asamblea más conformación de Asamblea Constituyente y posterior aprobación mediante referendo. También existe un procedimiento para la aprobación de leyes de reforma que debe contar con el apoyo de dos tercios de la Asamblea General para que luego sea votada en referendo. Sin embargo, ambos procedimientos poseen un grado de dificultad mayor, pero estos cauces alternativos no constituyen procesos obligatorios para cambiar capítulos específicos de la Constitución.

Como se puede observar, el ordenamiento jurídico uruguayo tiene disposiciones relativamente permisivas para su reforma, no solamente por sus menores quórums legislativos, sino además porque permite a la ciudadanía la posibilidad de introducir iniciativas orientadas a reformar la Constitución pasando directamente a la consulta ciudadana sin necesidad de pasar por el poder legislativo.

A continuación se revisarán las reformas constitucionales efectuadas tras el retorno a la democracia, evidenciándose que las reformas no han implicado un deterioro del sistema democrático.

\section{PRINCIPALES REFORMAS CONSTITUCIONALES}

El sistema político uruguayo históricamente se caracterizó por la disputa entre los denominados colorados y blancos, con un amplio dominio de los primeros sobre los últimos, pese a prevalecer la coparticipación como práctica habitual. Sin embargo, tras la restauración de la democracia en 1985 y la restitución de la Constitución de 1966, el sistema de partidos se dividió en tres con la emergencia electoral del $\mathrm{FA}^{3}$. Pese a la división del sistema, la democracia

3 A partir de 1971 y tras el retorno a la democracia en 1985. 
uruguaya ha sido denominada como una «democracia de consenso» (Chasquetti y Buquet, 2004; Lánzaro, 2013), en la que los partidos han gozado de autonomía y han sido centrales en la conducción política del país.

Uno de los elementos interesantes de la democracia uruguaya tiene relación con que, pese a sus reducidos umbrales para reformas constitucionales, no han existido reformas que tiendan a lesionar el sistema democrático. Esto rompe con una de las principales proposiciones del constitucionalismo liberal, que sostiene que mientras menos rígida sea una constitución más probable es que se imponga la llamada tiranía de la mayoría. En Uruguay ha sucedido todo lo contrario, ya que a partir del Gobierno de Sanguinetti (1985-1990) se restituyeron los derechos políticos y las libertades civiles, sumado a que los legados institucionales del periodo autoritario fueron derogados (Chasquetti y Buquet, 2004). Por consiguiente, desde un inicio no se realizaron prácticas orientadas a socavar el régimen democrático una vez restaurado.

En materia de reformas constitucionales, tras el retorno a la democracia la Constitución ha sido modificada en cuatro oportunidades, tal y como se observa en la tabla 3. La primera reforma (1989) estuvo asociada al cálculo de las pensiones ${ }^{4}$. Posteriormente, en 1994, se aprobó la inconstitucionalidad de la alteración del valor en las pensiones y jubilaciones por rendición de cuentas (Moreira, 2004; Garmendia; 2010).

Tabla 3. Reformas constitucionales realizadas entre 1985 al presente

\begin{tabular}{cc}
\hline Ańo reforma & Contenido \\
\hline 1989 & Cambios en el cálculo de las pensiones \\
\hline 1994 & Inconstitucionalidad de la alteración en el valor de las pensiones \\
\hline 1996 & $\begin{array}{c}\text { a) Se incorpora la segunda vuelta presidencial; b) obligatoriedad } \\
\text { de presentar candidato presidencial único; c) eliminación de } \\
\text { la acumulación de sublemas para la elección de diputados, y } \\
\text { d) separación de elecciones nacionales de las territoriales. }\end{array}$ \\
\hline 2004 & Evita la privatización del agua \\
\hline
\end{tabular}

Fuente: Biblioteca Miguel de Cervantes, Buquet (1997) y Comparative Constitutions Project.

La tercera reforma fue efectuada en el año 1996. Esta ha sido la mayor revisión realizada al sistema constitucional uruguayo tras el retorno a la

4 Esta reforma será discutida en la sección asociada a participación política, debido a que fue una iniciativa ciudadana. 
democracia. La reforma contempló cambios al sistema de elecciones. Más en específico, se modificaron los siguientes elementos: a) para la elección presidencial se reemplazó la mayoría simple por mayoría absoluta con segunda vuelta en caso de que ningún candidato logre dicho umbral; b) obligatoriedad de candidato presidencial único; c) eliminación de la acumulación por sublemas para la elección de diputados, y (d) separación de las elecciones nacionales de las territoriales (Buquet, 1997).

La reforma se aprobó mediante referendo por muy estrecho margen, obteniendo la opción del «sí» un 50,5\% de los votos gracias a la alianza entre blancos y colorados. La reforma tuvo como propósito principal frenar la llegada del FA a la Presidencia ante su constante crecimiento electoral (Altman et al., 2011), manteniéndose el duopolio entre blancos y colorados.

Tal y como se puede observar en la tabla 4, el FA progresivamente comenzaba a acercarse a la Presidencia. Junto con ello, los ajustados resultados de la elección presidencial del año 1994 podrían considerarse como la principal amenaza contra colorados y blancos, por lo que la reforma de 1996 surge mediante un acuerdo entre ambos bloques políticos, aunque para las elecciones del 2004 el frenteamplismo logra igualmente llegar a la Presidencia (Buquet, 1997; Altman et al., 2011; Chasquetti y Buquet, 2004; Altman y Castiglioni, 2006).

\section{Tabla 4. Resultados (\%) elecciones presidenciales de los principales conglomerados}

\begin{tabular}{cccc}
\hline Ańo & Partido Colorado & Partido Blanco & Frente Amplio \\
\hline 1984 & 30,3 & 35 & 21,3 \\
\hline 1989 & 30,3 & 38,9 & 21,2 \\
\hline 1994 & 32,3 & 31,2 & 30,6 \\
\hline 1999 & 32,7 & 22,2 & 40,3 \\
\hline 2004 & 10,4 & 34,3 & 50,7 \\
\hline
\end{tabular}

Fuente: Buquet (2005).

Se podría señalar que la reforma de 1996 constituye una reforma destinada a lesionar la democracia. No obstante, la reforma de ninguna manera vulneró los derechos y libertades civiles. Paralelamente, el Frente Amplio aceptó los resultados del referendo de forma pacífica. Sobre este punto, Lanzaro (2013: 253) afirma: 
La reforma constitucional uruguaya de 1996 quedó pues plenamente encuadrada en la democracia de partidos —en los marcos de un sistema plural y competitivo, de robustos contrapuntos de oposición efectiva- adoptando un perfil por cierto muy distinto al que presentan las reformas constitucionales de corte adversativo y sin núcleos de oposición debidamente organizados, tramitadas en democracias sin partidos y con ínfulas anti-partido, que han proliferado en las última décadas en algunos países de América Latina (notoriamente en Bolivia, Ecuador y Venezuela).

En base a las características descritas en el párrafo anterior, es posible señalar que la reforma constitucional de 1996 no constituye un ejercicio abusivo del poder orientado a lesionar las bases del sistema democrático uruguayo. La reforma se gestó en los márgenes propios de todo sistema pluralista, además de que no tuvo efectos sobre el ejercicio de los derechos y libertades de la ciudadanía ni de los partidos políticos.

La cuarta y última reforma realizada a la Constitución fue efectuada en el año 2004. La enmienda prohibió la privatización del agua. Este punto será tratado en la siguiente subsección, dado que corresponde a una iniciativa presentada por los electores.

Con todo lo anterior, se puede señalar que ninguna de las reformas realizadas en Uruguay tras el retorno a la democracia han debilitado las bases del sistema democrático, pese a que posee una Constitución con reducidos grados de rigidez. A esto se añade la poca cantidad de veces que la carta fundamental ha sido reformada.

Estas conclusiones van en contra las expectativas teóricas del constitucionalismo liberal, debido a que constituciones de este tipo pondría bajo amenaza los derechos y libertades, sobre todo de las minorías, razón por la que Uruguay podría ser considerado como un caso atípico, dado que ha conseguido establecer un sistema democrático estable.

La siguiente subsección analizará un elemento que vuelve aún más distintivo al caso uruguayo, vinculado a que las bajas barreras de enmienda han permitido la participación ciudadana en el diseño de reformas constitucionales, sobre todo mediante la iniciativa ciudadana, incentivando el trabajo conjunto entre ciudadanía y partidos políticos, elemento que contribuye al fortalecimiento del sistema democrático.

\section{PARTICIPACIÓN CIUDADANA EN EL DISEÑO DE REFORMAS}

La Constitución de 1966 se enmarca dentro de una larga tradición constitucional de participación directa de la ciudadanía en la toma de decisiones, sobre todo mediante la celebración de plebiscitos y referendos (Lissidini, 1998). 
Mediante la actual Constitución uruguaya, la ciudadanía tiene la posibilidad de introducir reformas constitucionales sin necesidad de pasar por la voluntad del poder legislativo.

La menor rigidez de la Constitución de Uruguay ha facilitado el acercamiento entre ciudadanos y partidos políticos, especialmente el caso del FA, coalición que dentro de sus estrategias de vinculación ha apoyado el uso de mecanismos de democracia directa (incluyendo iniciativas de reforma constitucional), lo que ha significado al mismo tiempo apoyo tanto hacia sus candidaturas como hacia el sistema de partidos postdictadura (Luna, 2008; Altman, 2002).

En términos de participación de la ciudadanía en la elaboración de reformas, a partir de 1985 se han aprobado dos reformas constitucionales mediante el mecanismo de iniciativa ciudadana: la reforma al cálculo de las pensiones (1989) y la reforma que permitió la nacionalización del agua (2004), siendo esta la última modificación a la Constitución.

La reforma que constitucionalizó el cálculo de las pensiones nació desde el seno del movimiento de los jubilados, con el fin de mantener el valor de las prestaciones al nivel del salario promedio. La reforma nació como iniciativa ciudadana, contando con el apoyo de amplios sectores del Partido Colorado, Partido Blanco y la totalidad del Frente Amplio. La reforma se aprobó con un $72,5 \%$ de los votos emitidos a favor del «sí».

Es importante consignar la existencia de trabajos que hacen un exhaustivo análisis de los efectos económicos adversos que generó esta reforma sobre las finanzas públicas (Rilla, 2008; Garmendia, 2010). Sin embargo, la evaluación de los efectos económicos de las reformas constitucionales no forma parte de los objetivos del presente trabajo. Pese a esto, es relevante consignar que la iniciativa ciudadana de reforma de 1989, más allá de su amplio apoyo en el referendo del mismo año, permitió a la ciudadanía incidir en el diseño de reformas constitucionales, sumado a que la propuesta contó con el apoyo transversal de los principales partidos políticos, abriéndose las puertas para un trabajo mancomunado entre ciudadanía e instituciones representativas.

La segunda reforma que surgió mediante iniciativa ciudadana es la del ańo 2004, consistente en la nacionalización del agua. La enmienda fue promovida por la CNDAV (Comisión Nacional en Defensa del Agua y de la Vida) y respaldada por el FA, encabezado por su entonces candidato presidencial Tabaré Vázquez y por varias organizaciones de trabajadores. La iniciativa fue aprobada en el referendo de 2004 con el 64,58\% de las preferencias (Dugard

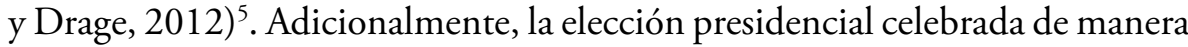
simultánea con el referendo dio la victoria en primera vuelta al FA.

5 Véase: https://bit.ly/3sVJBPO. 
En términos concretos, la reforma constitucionalizó el acceso al agua, garantizándola como derecho humano fundamental, cuya administración debe contemplar la participación de sus usuarios y de la sociedad civil en su conjunto, actores que tras dos años de trabajo lograron introducir esta reforma en medio de un agitado periodo de crisis económica (véase gráfico 1) y de privatización de empresas públicas, implicando un notable triunfo de la ciudadanía (Harris y Roa, 2012 ; Dugard y Drage, 2012)

\section{Gráfico 1. Crecimiento económico en Uruguay (1990-2010)}

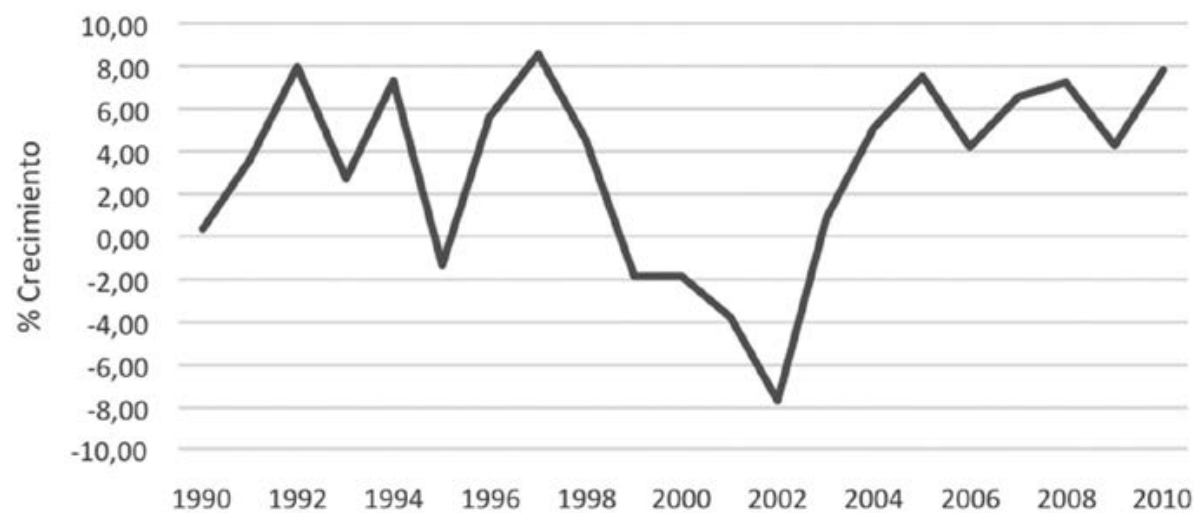

Fuente: Banco Mundial.

En concreto, el caso de Uruguay ilustra que es posible que constituciones más flexibles vayan de la mano junto a democracias electorales estables y a una baja frecuencia en el número de oportunidades en que la constitución es enmendada. Por otra parte, el estudio de Uruguay como caso atípico a los supuestos del liberalismo ha permitido visualizar que la menor rigidez de su carta fundamental ha permitido también la participación de la ciudadanía en el diseño de reformas constitucionales en conjunto con los partidos políticos, elemento que sin duda podría incluso llevarnos a afirmar que los mecanismos de democracia directa pueden ser utilizados para reforzar los cauces propios de la democracia representativa. Asimismo, también se podría añadir que esta menor rigidez puede llevar a contribuir a resolver uno de los problemas propios de la extrema rigidez constitucional: la falta de adaptabilidad a las demandas del entorno. En ese aspecto, la Constitución de 1966, pese a su bajo número de reformas, ha facilitado la adaptación del sistema constitucional a las demandas existentes, sobre todo tras la reforma de 2004, la que se gestó en medio de una crisis económica y de privatización de servicios, llevando a la nacionalización del agua. En ese sentido, la siguiente sección discutirá de 
modo general los potenciales problemas que puede generar la extrema rigidez constitucional más allá de las hipótesis establecidas por la teoría liberal.

\section{ALGUNOS ALCANCES SOBRE LA RIGIDEZ CONSTITUCIONAL EXTREMA}

Como ya se ha discutido, el liberalismo señala que mientas más rígidas sean las constituciones, más estables serán los sistemas democráticos. No obstante, uno de los principales problemas que pueden tener las constituciones con altas barreras para su reforma es la baja capacidad de respuesta del ordenamiento constitucional a las demandas de su entorno. Dicho en otras palabras, esto puede conducir a la baja capacidad que puede tener un sistema político para procesar reformas constitucionales demandadas por la ciudadanía, lo que puede llegar a generar una deslegitimación del orden constitucional imperante en el largo plazo.

A nivel comparativo, la evidencia apunta a que mientras más altas son las barreras para la enmienda, menor es la durabilidad de una Constitución (Elkins et al., 2009; Negretto, 2012). Dicho en otras palabras: a mayor flexibilidad, mayor tiempo durará una constitución, principalmente porque esta se irá adecuando a las diversas demandas que su entorno va imponiendo.

Respecto a casos históricos en América Latina contemporánea, podemos encontrar constituciones rígidas con un periodo de duración significativo, pero que a la postre terminaron siendo reemplazadas o se encuentran en proceso de reemplazo por su falta de adaptación. Para ello me referiré a dos casos particulares: Venezuela y Chile.

\section{VENEZUELA}

Venezuela bajo la Constitución de 1961 estableció las bases del llamado Pacto de Punto Fijo, fundándose las bases de un modelo de democracia de consenso denominado como partidocracia (Coppedge, 1994) entre los partidos Alianza Democrática (AD) y el Comité Político Electoral Independiente (COPEI), quienes administraron el poder en Venezuela durante prácticamente treinta años. Una de las principales características de dicha constitución fue su extrema rigidez.

Para aprobarse una reforma, el capítulo XV establecía como umbral la aprobación por mayoría absoluta en ambas cámaras, además de contar con la aprobación de la mayoría en cada una de las asambleas regionales para, finalmente, en sesión conjunta de ambas cámaras a nivel nacional, escrutar y considerar como aprobadas las disposiciones que hayan contado con el respaldo de 
dos tercios de las asambleas. Los únicos actores con poder de iniciativa fueron el Congreso y las asambleas regionales. Esta rigidez permitió que la Constitución fuese aprobada en tan solo dos oportunidades. La primera de ellas (1973) consistió en cambios menores relativos a las condiciones para presentar candidaturas presidenciales, bloqueando la eventual candidatura del exdictador Marcos Pérez Jiménez (Brewer-Carias, 1982). La segunda enmienda llegó una década después, en 1983. Dentro de las iniciativas aprobadas destaca la modificación a las reglas electorales en los consejos municipales y las asambleas legislativas, así como también la creación de las comisiones legislativas del Congreso y la rebaja de los quórums legislativos para sesiones parlamentarias ${ }^{6}$.

Uno de los grandes problemas que tuvo el sistema constitucional venezolano fue la falta de canales de participación. La estructura de participación del sistema de Punto Fijo ha sido considerada como rígida (Crisp, 2000; Crisp y Levine, 1998), puesto que la única forma de participación ciudadana era mediante un sistema semicorporativo en el que los actores económicos y sociales podían ser escuchados siempre y cuando participaran en el marco de las estructuras partidarias tradicionales (Coppedge, 1994, 1995).

La partidocracia permitió una intermediación eficaz, pero aquellos grupos de la ciudadanía que gozaban de mayor autonomía frente al Estado y los partidos políticos se encontraron sin acceso a cauces institucionales que hicieran sentir su voz. Lo anterior, sumado a la ausencia de partidos que representaran a estos sectores y la no existencia de un partido o coalición reformista en esta materia, relegó a la clase media a un espiral de silencio que duró casi treinta años a pesar de la promesa de extender la participación ciudadana más allá de la emisión del voto. No obstante, esta promesa se fue desvaneciendo en el tiempo. De hecho, ninguna medida adoptada por el sistema implicó que las instituciones representativas compartieran poder político junto con la ciudadanía (Añez et al., 2003). Complementariamente, las reformas constitucionales no contaron con la participación de los electores en su diseño, por lo que el bloqueo constante a las demandas por participación directa permitió la penetración de nuevas ideas asociadas a la inclusión de la ciudadanía en los temas de interés público de forma sustantiva, amparados en el modelo de democracia bolivariana (Sanoja, 2009).

Durante los primeros años de la crisis económica (1984) se creó una comisión encabezada por el presidente Jaime Lusinchi denominada Comisión Presidencial para la Reforma del Estado (COPRE), en un intento por buscar una solución política a la crisis por la que estaba atravesando el país.

Los miembros de la comisión enfatizaron la necesidad de implementar la elección directa de alcaldes y gobernadores regionales, además de otras

6 Véase: https://bit.ly/3qT7nu7. 
propuestas, tales como reformas al sistema de financiamiento de los partidos y sus procedimientos internos. El paquete de propuestas fue rechazado principalmente por $\mathrm{AD}$ al considerarlo demasiado radical (Lalander, 2008) ${ }^{7}$. La discusión de las reformas quedaría postergada hasta 1989, año en que se vive uno de los grandes conflictos de fines de los ochenta: el Caracazo (1989).

La falta de respuestas satisfactorias por parte del sistema también llevó a la organización de los militares. Fruto de ello fue la Conformación del MBR-200 (Movimiento Bolivariano Revolucionario 200), que ganó protagonismo político en 1989 y fue artífice de dos intentos fallidos de golpe de Estado fruto de la parálisis institucional (Lalander, 2008). Este panorama de mayor distanciamiento entre ciudadanía y partidos políticos ponía cada vez más de manifiesto el clamor de la sociedad por abrir mayores canales de participación directa, tal y como se observa en la tabla 5 .

Tabla 5. Preferencias ciudadanas en materia de reformas politicas (\%)

\begin{tabular}{lccc}
\hline & $\mathbf{1 .}^{\mathbf{a}}$ opción & 2.a opción & $\begin{array}{c}\text { Última } \\
\text { opción }\end{array}$ \\
\hline $\begin{array}{l}\text { Incrementar la participación directa de la } \\
\text { ciudadanía }\end{array}$ & 38 & 14 & 6 \\
\hline Elección directa de alcaldes y gobernadores & 23 & 9 & 7 \\
\hline $\begin{array}{l}\text { Garantizar que los detenidos sean formalizados } \\
\text { o liberados tras 24 horas }\end{array}$ & 15 & 13 & 14 \\
\hline $\begin{array}{l}\text { Establecer defensores ciudadanos en el nivel } \\
\text { estatal y local }\end{array}$ & 8 & 21 & 10 \\
\hline $\begin{array}{l}\text { Proteger al poder judicial de la influencia } \\
\text { económica y partidista }\end{array}$ & 5 & 17 & 7 \\
\hline $\begin{array}{l}\text { Descentralizar el Gobierno } \\
\text { Reorganizar el poder ejecutivo }\end{array}$ & 5 & 12 & 12 \\
\hline Democratizar los partidos políticos & 1 & 3 & 12 \\
\hline No sabe / no responde & 4 & 6 & 14 \\
\hline
\end{tabular}

$\mathrm{N}=7654$

Fuente: Myers $(1995)^{8}$.

7 Aunque en 1989 se lleva adelante la elección de directa de alcaldes y gobernadores.

8 Sondeo realizado en 1989. 
En 1989, durante la Administración de Carlos Andrés Pérez, en búsqueda de una solución política tras el creciente malestar ciudadano, nuevamente se comienza a debatir la posibilidad de realizar reformas constitucionales (Navarro, 1995). Incluso, algunos sectores contrarios a los partidos tradicionales comenzaron a defender la idea de conformar una Asamblea Constituyente para la creación de una nueva Constitución', idea que con el transcurso del tiempo fue adquiriendo mayor fuerza ${ }^{10}$.

En concreto, la propuesta de reforma constitucional encabezada por Pérez fue desechada en 1992, año en el que hubo dos intentos de golpe de Estado que gozaron de amplio apoyo popular en reacción a la falta de respuestas institucionales (Philip y Murillo, 2004).

El intento de golpe sirvió para que los actores políticos buscaran un nuevo acuerdo para poder realizar reformas al sistema (Kornblith, 1996; Navarro, 1995). Es en ese instante cuando amplios sectores, sobre todo de la izquierda, comenzaron a exigir una nueva Constitución y mayores canales de participación directa de la ciudadanía, ideas que habían sido largamente postergadas desde mediados de la década de los setenta (Añez et al., 2003).

En respuesta, Carlos Andrés Pérez anuncia un plebiscito para el llamado a elecciones para la conformación de una Asamblea Constituyente como medio para: «reformular el sistema y transferir al pueblo la solución global de la crisis ${ }^{11}$. El referendo no se realiza. Sin embargo, se designa a una comisión bicameral para que elabore un proyecto de reforma.

El intento de reformar la Constitución en 1992 fracasó porque no tuvo apoyo por parte de los partidos tradicionales, cuestionándose por primera vez la legitimidad de la Constitución de 1961 (López Maya, 2014). Debido a que gran parte de las reformas estaban orientadas a volver el sistema político más participativo, sumado a los ajustes en el sistema de separación de poderes, los representantes en el Congreso calificaron que un paquete de enmiendas tan profundo no iba a ser aprobado en el referendo. Añadido a que no era conveniente realizar reformas en periodos de inestabilidad, el Congreso optó por la deslegitimación del sistema en lugar de proponer reformas (Navarro, 1995). Tomando en consideración estos acontecimientos, la reforma a la Constitución se estancó, debido a que la iniciativa no contó con la venia de los partidos tradicionales, y se impuso la rigidez de la Constitución para realizar cambios.

\footnotetext{
9 Aunque para eso había que reformar la Constitución de 1961, puesto que no contemplaba canales institucionales para su reemplazo.

10 Véase Brewer-Carías (2001).

11 Véase: https://bit.ly/3ofMx6f.
} 
La parálisis mencionada llevó a un segundo intento de golpe de Estado. Pese a fracasar, el intento contó nuevamente con respaldo popular. El evento dejó un negativo precedente: la poca capacidad de respuesta del sistema llegó a un punto en el que la opinión pública comenzó a respaldar conductas de corte autoritario (Philip y Murillo, 2004).

Como alternativa a la falta de respuestas de los partidos surge el llamado Polo Patriótico, compuesto por el Movimiento Quinta República (MVR), MAS, Partido Comunista y Patria para Todos (PPT) bajo el liderazgo de Hugo Chávez. El proyecto político de Chávez proponía una refundación total, tanto en lo económico como en lo político. Respecto a lo político, su campaña se basó en la promesa de convocar una Asamblea Constituyente encargada de diseñar una nueva Constitución, (Lalander, 2012; Viciano y Martínez, 2000). Adicionalmente, la nueva Constitución tenía como objeto reemplazar el modelo de democracia representativa heredado del puntofijismo por uno de democracia bolivariana, es decir, destinado a otorgar mayores herramientas de participación directa a la ciudadanía (Braver, 2017).

Chávez ganó la elección presidencial el 6 de diciembre de 1998 con el $56 \%$ de los votos. Una vez que asumió el cargo de presidente, inició de inmediato el proceso constituyente convocando a un plebiscito. La razón de esto último radica en que la rigidez de la carta de 1961 iba a asegurar como resultado el rechazo por parte de la oposición. Por consiguiente, la decisión del Gobierno consistió en pasar por alto a las instituciones de contrapeso, y esta acción fue aprobada por la justicia constitucional (Brewer Carías, 2001; Braver, 2017; Kornblith, 2003).

Como resultado, la opción del «si» obtuvo un $81 \%$ de respaldo, lo que llevó a la confección de la Constitución de 1999. La carta fundamental de 1999 ha significado una gran concentración del poder político en manos del Ejecutivo, sumado a que sus reformas han permitido la reelección indefinida de la figura del presidente y una mayor dependencia de la justicia electoral y constitucional hacia la figura del primer mandatario (McCoy, 2010; Sánchez, 2016).

En conclusión, la Constitución de 1961 sentó las bases institucionales para un sistema que fue administrado por casi treinta años por $\mathrm{AD}$ y COPEI en virtud de los acuerdos alcanzados por medio del Pacto de Punto Fijo. Esto llevó al establecimiento de una Constitución con altos grado de rigidez. Si bien esta rigidez permitió por varios ańos llevar adelante un modelo de democracia estable, con el correr de los años comenzó a evidenciarse las falencias en materia de diseño. En primera instancia, la rigidez de la Constitución neutralizó las demandas por intensificar la participación directa de la ciudadanía, siendo esta una de las principales demandas ciudadanas tras la transición a la democracia. Esta demanda se radicaliza tras la crisis económica iniciada en 1983, cuyo punto álgido estalla en 1989. Ninguna de las reformas realizadas 
estuvo en línea con lo que la ciudadanía esperaba. Del mismo modo, ante la crisis económica la Constitución de 1961 no tuvo la capacidad de adecuarse para brindar herramientas para la resolución de conflictos en un periodo política y económicamente adverso. Esto último condujo al surgimiento de posturas radicalizadas, encabezadas por Hugo Chávez, quien organizó dos golpes de Estado fallidos en 1992 y que gozaron de amplio apoyo popular. Sin embargo, pese a que los intentos fracasaron, esto no impidió que Chávez llegara al poder en 1999 por la vía electoral, reemplazando la Constitución en el mismo año con serias consecuencias para la democracia venezolana.

\section{CHILE}

La actual Constitución política de 1980 fue promulgada bajo el Gobierno autoritario de Augusto Pinochet. Diseñada para no sufrir cambios profundos, la carta fundamental posee desde sus orígenes una serie enclaves que la han dotado de una extrema rigidez. Con quórums legislativos que incluso llegan a los dos tercios en un sistema bicameral, sumado a un sistema electoral conocido como binominal (reemplazado por un sistema con formula D'Hondt para las elecciones legislativas de 2017) que sobrerrepresentó a los partidos que fueron aliados del antiguo régimen, más un Tribunal Constitucional cuyas decisiones son más bien de orden político que jurídico - transformándose en una suerte de tercera cámara (Bassa, 2015)_, más la presencia de senadores vitalicios y designados (removidos con la reforma de 2005), han otorgado un amplio poder de veto tanto a los partidos de derecha Renovación Nacional $(\mathrm{RN})$ como a la Unión Demócrata Independiente (UDI). El sistema constitucional descrito ha sido denominado por la literatura como un sistema «sesgado hacia las elites» (Albertus y Menaldo, 2018) o como una «democracia semisoberana» (Huneeus, 2016).

La rigidez del sistema constitucional era un objetivo perseguido por sus creadores, especialmente Jaime Guzmán, quién fue el principal asesor civil del régimen, cuyo propósito consistió en diseñar una serie de dispositivos destinados a neutralizar cualquier intento por parte de alguna coalición reformista una vez restaurada la democracia: «La Constitución debe procurar que, si llegan a gobernar los adversarios, se vean constreñidos a seguir una acción no tan distinta a la que uno mismo anhelaría, porque — valga la metáfora — el margen de alternativas posibles que la cancha imponga de hecho a quienes juegan en ella sea lo suficientemente reducido para hacer extremadamente difícil lo contrario» ${ }^{12}$.

Tras el retorno a la democracia, el respeto a la Constitución por parte de la Concertación —coalición de partidos compuesta por la Democracia Cristiana

12 Fuente: El Ciudadano. Disponible en: https://bit.ly/3pfKgtl. 
(DC), Partido Socialista (PS), Partido por la Democracia (PPD) y Partido Radical (PR) - permitió una transición pacífica hacia la democracia (Heiss y Navia, 2007). La rigidez de la Constitución por medio de sus disposiciones supramayoritarias incentivó la formación de una democracia de consenso entre los principales bloques políticos del país, conocida como la «democracia de los acuerdos» (Siavelis, 2006; Alberts et al., 2012), introduciéndose reformas menores a la Constitución hasta llegado el año 2005, periodo en el que se realizó la mayor reforma a la carta fundamental al eliminarse enclaves tales como la presencia de senadores vitalicios y designados y la remoción del sistema electoral binominal de la Constitución, que pasó a ser Ley Orgánica Constitucional. También se efectuaron otras enmiendas orientadas a reducir la influencia de los militares en los asuntos civiles (Fuentes, 2012a). No obstante, las reformas realizadas en ese entonces fueron bajo un esquema basado en pactos de elite de los partidos políticos con exclusión de la ciudadanía (Fuentes, 2012b).

Desde el año 2006 en adelante comienza a surgir un cúmulo de demandas sociales destinadas al reconocimiento de derechos sociales en un modelo constitucional en el que el Estado fue reducido a un rol subsidiario como parte de las reformas de mercado introducidas al país desde 1975.

El primer movimiento social en manifestarse fueron los estudiantes secundarios (2006), quienes mediante multitudinarias protestas deslegitimaron las leyes orgánicas constitucionales. Específicamente hay que citar la ley en materia de educación (Donoso, 2013).

A partir de 2011 la Constitución comienza a cimentar su progresiva deslegitimación gracias al movimiento de estudiantes universitarios, quienes demandaron mediante multitudinarias protestas a nivel nacional la universalización del derecho a la educación superior, que debía ser constitucionalizado. La demanda no logró llegar al nivel constitucional. En conjunto, comenzaron a sumarse las demandas por reformas al sistema de pensiones, el reconocimiento de los pueblos originarios, de las minorías sexuales y los derechos medioambientales. Ninguna de las demandas logró ser exitosa, por lo que el elemento común entre todos estos movimientos fue uno solo: una nueva Constitución para Chile (Donoso, 2013; Observatorio del Proceso Constituyente de Chile, 2017; Von Bullow y Bidegaín, 2015; Heiss, 2017).

Michelle Bachelet en su segundo periodo presidencial (2014-2018) recoge estas demandas, abriendo un proceso constituyente mediante una etapa participativa sin precedentes en la historia reciente del país ${ }^{13}$. Sin embargo, el proceso

13 Véase, discurso de inicio del proceso constituyente. Disponible en: https://bit. ly/3ccl7vN. 
fracasó tras no superar la barrera de los dos tercios para introducir mediante la vía institucional mecanismos destinados al reemplazo constitucional. Pese al fracaso del proceso, la gran mayoría de la opinión pública respaldaba una nueva Constitución, cuyo principal argumento estuvo basado en que el actual ordenamiento es incompatible con los tiempos actuales, y también por sus orígenes autoritarios, como refleja la tabla 6 .

Tabla 6. Necesidad de cambios a la Constitución, importancia del cambio constitucional y razones para el cambio

\begin{tabular}{|c|c|c|}
\hline Pregunta & Respuesta & $\%$ \\
\hline \multirow{3}{*}{$\begin{array}{l}\text { Dígame, por favor, si en la Constitución política } \\
\text { se necesitan "cambios profundos», } \\
\text { "cambios moderados» o «no necesita cambios». }\end{array}$} & Cambios profundos & 66 \\
\hline & Cambios moderados & 22 \\
\hline & No necesita cambios & 3 \\
\hline \multirow{2}{*}{$\begin{array}{l}\text { Y pensando en los desafíos de Chile ¿qué tan importante le } \\
\text { parece a usted cambiar la Constitución política de Chile? }\end{array}$} & Muy importante & 56 \\
\hline & Bastante importante & 28 \\
\hline \multirow{3}{*}{$\begin{array}{l}\text { De las siguientes razones, ¿cuál es para usted } \\
\text { la principal por la que hay que cambiar } \\
\text { la Constitución política de Chile? }\end{array}$} & $\begin{array}{l}\text { Porque su contenido no } \\
\text { sirve para los actuales } \\
\text { desafíos del país }\end{array}$ & 54 \\
\hline & $\begin{array}{l}\text { Porque se originó en } \\
\text { dictadura }\end{array}$ & 15 \\
\hline & Ambas razones & 19 \\
\hline
\end{tabular}

Fuente: Programa de Naciones Unidas para el Desarrollo (2016) ${ }^{14}$.

La demanda por una nueva Constitución volvería a cobrar fuerza en el mes de octubre de 2019. El día 18 de octubre, tras una semana de evasiones masivas del metro de Santiago por parte de estudiantes secundarios en respuesta a una considerable alza en el valor de su pasaje, llevó a que el Gobierno de Sebastián Piñera (derecha) reprimiera con violencia las evasiones. En respuesta a la violenta represión estatal, la ciudadanía salió a protestar - en su mayoría de forma pacífica-, tomando las calles de Santiago y del resto del país exigiendo cambios profundos al sistema político y económico. Tras una serie de hechos de violencia como la quema de estaciones de metro y saqueos a supermercados, el Gobierno decretó toque de queda a nivel nacional para

14 Informe auditoría a la democracia 2016. Disponible en: https://bit.ly/39gItyC. 


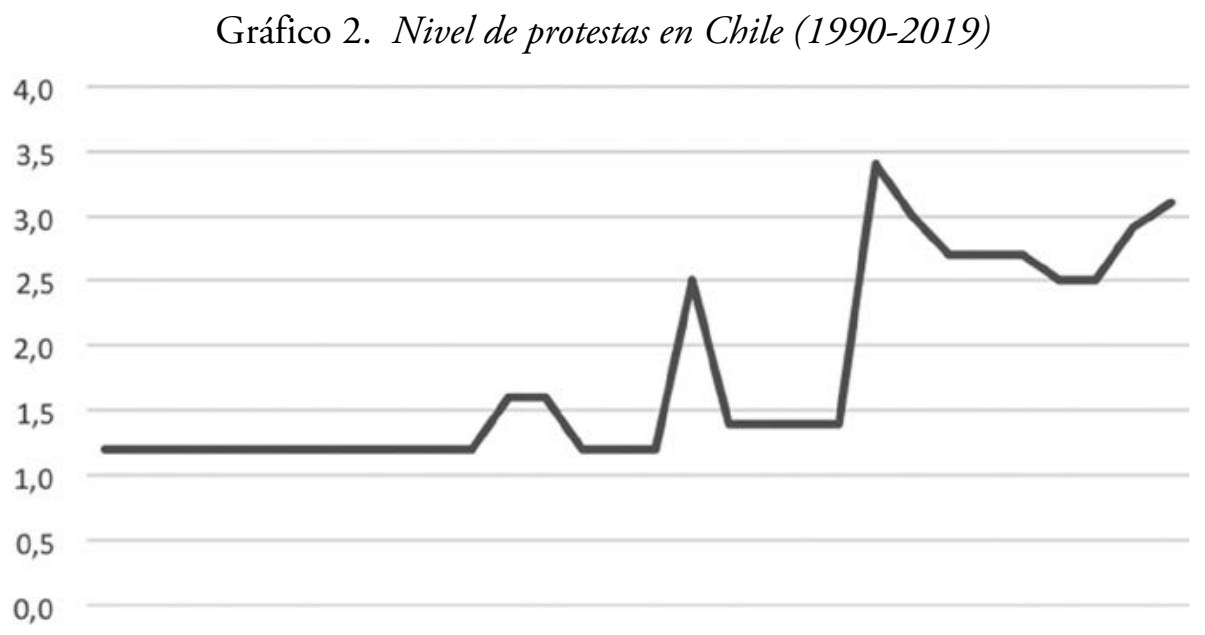

199019921994199619982000200220042006200820102012201420162018

$0=$ no ha habido protestas.

$1=$ varios eventos de baja escala.

2 = muchos eventos de baja escala.

$3=$ varios eventos de larga y baja escala.

$4=$ muchos eventos de larga y baja escala.

Fuente: Varieties of Democracy.

restaurar el orden, declarando la guerra a los manifestantes: «Estamos en guerra contra un enemigo poderoso»" ${ }^{15}$.

El rechazo a la violencia estatal y la falta de respuesta del Gobierno para introducir reformas de fondo al sistema político y económico llevó a más de un millón y medio de manifestantes a las calles de Santiago a una masiva protesta pacífica que exigía, principalmente, una nueva Constitución ${ }^{16}$.

Finalmente, tras largas jornadas de protestas, tanto violenta como no violenta, junto a graves violaciones a los derechos humanos por parte de Carabineros (según informes de Humans Rights Watch ${ }^{17}$ ), el 15 de noviembre el Congreso acuerda las bases para un plebiscito destinado a consultar a la ciudadanía su voluntad de reemplazar o mantener la actual Constitución. El plebiscito originalmente estaba contemplado para el mes de abril. Sin embargo, producto del dańo provocado por la COVID-19, el cronograma fue aplazado para el 25 de octubre de 2020.

15 Fuente: CNN Chile. Disponible en: https://cutt.ly/MkfHsyL.

16 Fuente: BBC en español. Disponible en https://bbc.in/3ojRtqF.

17 Véase: https://bit.ly/2MpVRan. 
En síntesis, en Chile desde 2006 comienza a incrementarse el nivel de protestas ante mayores demandas por cambios a la estructura política y al modelo económico, llegando a la progresiva petición del cambio constitucional. Los datos reflejados en el gráfico 2 muestran un aumento importante en las protestas justamente en los años 2006, 2011 y 2019. Adicionalmente, el nivel de protestas en el país desde 2011 hasta 2019 jamás descendió a los niveles del periodo 1990-2005, lo que refuerza la idea de una creciente movilización social por cambios estructurales.

El caso de Chile, al igual que Venezuela, muestra que elevados niveles de rigidez no necesariamente garantizan la estabilidad del régimen democrático en el largo plazo. En ambos países se observan dos partidos/coaliciones electorales que lograron mediante la rigidez constitucional crear sistemas estables, sumado a democracias de consenso (partitocracia y democracia de los acuerdos). No obstante, en el largo plazo, tanto la Constitución de 1961 como la Constitución de 1980 fracasaron en su intento de absorber los cambios demandados por la ciudadanía. En el caso de Venezuela, la parálisis institucional en medio de una severa crisis económica llevó a dos intentos fallidos de golpe de Estado, mientras que en Chile (en ausencia de crisis económica) el sistema llegó a un evidente colapso, llevando al estallido social más grande tras el retorno a la democracia y abriéndose paso a un proceso constituyente cuyo resultado está por definir. En ambos casos también se observa que las reformas realizadas no solamente fueron moderadas, sino que también fueron producto de acuerdos entre las elites, quedando la ciudadanía al margen del diseño de reformas.

En Uruguay sucede todo lo contrario, ya que sus reglas menos rígidas han permitido la incorporación de la ciudadanía en el diseño de reformas (especialmente en 1989 y 2004) e, incluso, han permitido la introducción de reformas demandadas por la población en medio de una aguda crisis económica, como ocurrió con la reforma de 2004. Si se compara con Venezuela, país que también se vio enfrentada a demandas ciudadanas por reformas constitucionales en medio de crisis económica, este último país se vio en medio de una parálisis con consecuencias negativas para la democracia, lo que llevó a la deslegitimación del orden constitucional. En cambio, en Uruguay la participación ciudadana en la reforma de 2004 muestra la adaptabilidad de la Constitución a las exigencias de su entorno sin deterioro de ninguno de los componentes propios de la democracia electoral.

\section{CONCLUSIONES}

La presente investigación ha tenido como objeto problematizar acerca de si constituciones más flexibles (o menos rígidas) generan impactos negativos 
sobre los regímenes democráticos. De acuerdo a la teoría constitucional liberal, mientras más altas sean las barreras para la enmienda, mayor será su efecto positivo sobre la democracia. Con el objeto de evidenciar que constituciones más permisivas para su modificación no siempre generan efectos negativos se ha estudiado el caso de Uruguay.

La selección del caso uruguayo corresponde a un caso atípico, ya que presenta elevados índices en cuanto al funcionamiento de la competencia electoral y un correcto funcionamiento del sistema de contrapesos. Adicionalmente, dicho país presenta los mayores niveles de participación política de América Latina, y presenta bajas barreras para la reforma constitucional.

El estudio de caso muestra que, contrario a las expectativas teóricas del liberalismo, ninguna de las reformas introducidas en la Constitución uruguaya ha vulnerado la democracia electoral. Por otra parte, su baja rigidez ha hecho protagonista a la ciudadanía en el diseño de cambios en la Constitución por medio de las reformas de 1989 y 2004.

En oposición al caso uruguayo también se han explorado dos casos de estudio adicionales asociados a que elevados niveles de rigidez no necesariamente aseguran la estabilidad del sistema democrático: Venezuela y Chile. Ambos países constituyeron tras la transición a la democracia dos modelos estables de democracia de consenso bajo reglas rígidas de enmienda.

En el caso venezolano, la rigidez impidió reformas que expandieran la participación política más allá de las elecciones, principalmente durante la parálisis institucional en medio de una crisis económica que llevó a dos intentos de golpe de Estado en 1992 y el posterior ascenso al poder de Hugo Chávez y el reemplazo de la Constitución de 1961 en 1999.

En Chile, a partir de 2006 comienzan a surgir una amplia serie de demandas sociales por mayores derechos sociales. La falta de respuesta del sistema constitucional incrementó la oleada de protestas, llegando en octubre de 2019 al mayor estallido social tras el retorno a la democracia. Tras largas jornadas de protestas violenta y no violenta, en el mes de noviembre se abrieron los caminos para un proceso constituyente cuyo resultado está por definir tras el término de la pandemia ocasionada por la COVID-19.

Los casos de Uruguay, Chile y Venezuela llevan a repensar los supuestos del liberalismo, sobre todo la necesidad de hacer una revisión empírica más amplia acerca de la veracidad de la relación existente entre rigidez constitucional y estabilidad de la democracia. Casos históricos como el de Bolivia y la rigidez de la Constitución de 1967 y su falta de respuesta de cara al reconocimiento de los pueblos indígenas (que terminó en el reemplazo constitucional de 2009), así como también la reducción de las barreras de enmienda en Colombia para introducir las reformas que permitieron los acuerdos entre el Estado Colombiano y la FARC por vía fast track, exigen un examen acerca de la validez externa 
de este supuesto, principalmente sobre hasta qué punto las democracias cumplen con su función de adaptación/respuesta (responsiveness) ante las demandas ciudadanas cuando las barreras para la enmienda son elevadas.

\section{Bibliografía}

Alberts, S., Warshaw, C. y Weingast, B. (2012). Democratization and Countermajoritarian institutions: Power and Constitutional Design in Self-Enforcing Democracy. En T. Ginsburg (ed.). Comparative Constitutional Design (pp. 69-100). Cambridge: Cambridge University Press.

Albertus, M. y Menaldo, V. (2018). Authoritarianism and the Elite Origins of Democracy. Cambridge: Cambridge University Press. Disponible en: https://doi.org/10.1017/9781108185950.

Altman, D. (2002). Popular initiatives in Uruguay: confidence votes on governments or political loyalties? Electoral Studies, 21, 617-630. Disponible en: https://doi.org/10.1016/ S0261-3794(01)00036-1.

Altman, D. (2008). Collegiate Executives and Direct Democracy in Switzerland and Uruguay: Similar Institutions, Opposite Political Goals, Distinct Results. Swiss Political Science Review, 14 (3), 483-520. Disponible en: https://doi.org/10.1002/j.1662-6370.2008. tb00110.x.

Altman, D., Buquet, D. y Luna J. P. (2011). Constitutional Reforms and Political Turnover in Uruguay: Winning a Battle, Losing the War. Documento Online, 2-11. Montevideo: Instituto de Ciencia Política de la Facultad de Ciencias Sociales de la Universidad de la República. Disponible en: https://bit.ly/3qPAOgo.

Altman, D. y Castiglioni, R. (2006). The 2004 Uruguayan elections: A political earthquake foretold. Electoral Studies, 25, 147-191. Disponible en: https://doi.org/10.1016/j. electstud.2005.06.005.

Añez, C., López M. y Suárez, W. (2003). El Estado venezolano y la participación ciudadana. Espacio Abierto, 12 (4), 579-603.

Bassa, J. (2015). El Tribunal Constitucional en la Constitución chilena vigente. En J. Bassa, J. C. Ferrada y C. Viera (eds.). La Constitución chilena: una revisión crítica a su práctica politica (pp. 253-284). Santiago de Chile: LOM ediciones.

Braver, J. (2017). Revolutionary Reform in Venezuela: Electoral Rules and Historical Narratives in the Creation of the 1999 Constitution. En R. Albert, X. Contiades y A. Fotiadou (eds). The Foundations and Traditions of Constitutional Amendment (pp. 137-156): Oxford, Oregon: Hart Publishing.

Brewer-Carías, A. (1982). El Estado, crisis y reforma. Caracas: Academia de Ciencias Políticas y Sociales.

Brewer-Carías, A. (2001). Golpe de Estado y proceso constituyente en Venezuela. Ciudad de México: Universidad Nacional Autónoma de México.

Bryce, J. (1952). Constituciones flexibles y constituciones rigidas. Madrid: Instituto de Estudios Políticos.

Buchanan, J. y Tullock, G. (1999) [1962]. The Calculus of Consent: Logical Foundations of Constitutional Democracy. Indianapolis: Liberty Fund. 
Buquet, D. (1997). Reforma política y gobernabilidad democrática en Uruguay: la reforma constitucional de 1996. Revista Uruguaya de Ciencia Politica, 10, 9-24.

Buquet, D. (2005). Las claves del cambio: ciclo electoral y nuevo gobierno 2004-2005. Montevideo: EBO-ICP.

Chasquetti, D. y Buquet, D. (2004). La democracia en Uruguay: una partidocracia de consenso. Revista Política, 42, 221-247.

Closa, C. (2012). Constitutional Rigidity and Procedures for Ratifying Constitutional Reforms in EU Member States. En A. Benz y F. Knüpling (eds.). Changing Federal Constitutions (pp. 281-310). Berlín: Barbara Budrich. Disponible en: https://doi. org/10.2307/j.ctvddzh07.19.

Coppedge, M. (1994). Strong Parties and Lame Ducks: Presidential Partiarchy and Factionalism in Venezuela. Stanford: Stanford University Press.

Coppedge, M. (1995). Partidocracia and Reform in Comparative Perspective. En J. McCoy, A. Serbin y A. Stambouli (eds.). Venezuelan Democracy Under Stress (pp. 173-196). United States: Transaction Publishers.

Crisp, B. (2000). Democratic Institutional Design: The Powers and Incentives of Venezuelan Politicians and Interest Groups. Stanford: Stanford University Press.

Crisp, B. y Levine, D. (1998). Democratizing the Democracy? Crisis and Reform in Venezuela. Journal of Interamerican Studies and World Affairs, 40 (2), 27-61. Disponible en: https://doi.org/10.2307/166373.

Dahl, R. (1971). Polyarchy: Participation and Opposition. New Heaven: Yale University Press.

Dixon, R. y Landau, D. (2015). Transnational constitutionalism and a limited doctrine of unconstitutional constitutional amendment. International Constitutional Law, 13 (3), 606-638. Disponible en: https://doi.org/10.1093/icon/mov039.

Donoso, S. (2013). Dynamics of Change in Chile: Explaining the Emergence of the 2006 Pingüino Movement. Journal of Latin American Studies, 45 (1), 1-29. Disponible en: https://doi.org/10.1017/S0022216X12001228.

Dugard, J. y Drage, K. (2012). Shields and Swords: Legal Tools for Public Water. Occasional Paper, 17. Canada: Municipal Services Project.

Elkins, Z., Ginsburg, T. y Melton, J. (2009). The Endurance of National Constitutions. New York: Cambridge University Press. Disponible en: https://doi.org/10.1017/ CBO9780511817595.

Elster, J. (1995). Forces and Mechanisms in the Constitution Making Process. Duke Law Journal, 45, 364-396. Disponible en: https://doi.org/10.2307/1372906.

Fuentes, C. (2012a). El pacto: poder, constitución y prácticas politicas en Chile (1990-2010). Santiago de Chile: Ediciones Universidad Diego Portales.

Fuentes, C. (2012b). Chile: Democratization Through Constitutional Reforms. En N. Detlef y A. Schilling-Vacaflor (eds.). New Constitutionalism y Latin América: Promises and Practices (pp. 243-264). New York: Routledge.

Garmendia, G. (2010). Evaluación de la reforma del sistema de pensiones Uruguay. Perfiles Latinoamericanos, 35, 89-103.

Goertz, G. y Mahoney, J. (2012). A Tale of Two Cultures: Qualitative and Quantitative Research in the Social Sciences. Princeton: Princeton University Press. Disponible en: https://doi. org/10.23943/princeton/9780691149707.001.0001. 
González, R. (2008). Democracia directa: el Caso de Uruguay. En A. Lissidini, Y. Welp y D. Zovatto (eds.). Democracia directa en América Latina (pp. 171-190). Buenos Aires: Prometeo Libros.

Hamilton, A., Madison, J. y Jay, J. (2006) [1780]. El Federalista. México: Fondo de Cultura Económica.

Harris, L. y Roa, M. (2012). Recent waves of water governance: Constitutional reform and resistance to neoliberalization in Latin America (1990-2012). Geoforum 50, 20-30. Disponible en: https://doi.org/10.1016/j.geoforum.2013.07.009.

Heiss, C. (2017). Legitimacy crisis and the constitutional problem in Chile: A legacy of authoritarianism. Constellations, 24 (3), 470-479. Disponible en: https://doi.org/10.1111/14678675.12309.

Heiss, C. y Navia, P. (2007). You Win Some, You Lose Some: Constitutional Reforms in Chile's Transition to Democracy. Latin American Politics and Society, 49 (3), 163-190. Disponible en: https://doi.org/10.1111/j.1548-2456.2007.tb00386.x.

Huneeus, C. (2016). El régimen de Pinochet. Chile: Taurus.

King, G., Keohane, R. y Verba, S. (1994). Designing Social Inquiry: Scientific Inference in Qualitative Research. Princeton: Princeton University Press. Disponible en: https://doi. org/10.1515/9781400821211.

Kornblith, M. (1996). Crisis y transformación del sistema político venezolano: nuevas y viejas reglas del juego. Disponible en: https://bit.ly/3sT09YB.

Kornblith, M. (2003). Del Puntofijismo a la Quinta República: elecciones y democracia en Venezuela. Colombia Internacional, 58, 160-194. Disponible en: https://doi.org/10.7440/ colombiaint58.2003.06.

Landau, D. (2013). Abusive constitutionalism. UC Davis Law Review. 47, 189-260.

Lalander, R. (2012). Neo-Constitutionalism in Twenty-first Century Venezuela: Participatory Democracy, Deconcentrated Decentralization or Centralized Populism? En A. Schilling-Vacaflor (eds.). New Constitutionalism in Latin America: Promises and Practices (pp. 163-182). New York: Routledge.

Lalander, R. (2008). El contexto histórico del chavismo y los partidos políticos de izquierda. Reflexión Politica, 10 (19), 36-48.

Lanzaro, J. (2013). Continuidad y cambios en una vieja democracia de partidos, Uruguay (1910-2010). Opinao Pública, 19 (2), 235-269.

Levinson, S. (1995). Introduction: Imperfection and Amendability. En S. Levinson (ed.). Responding to Imperfection: Theory and Practice of Constitutional Amendment (pp. 3-11). Princeton, New Jersey: Princeton University Press. Disponible en: https://doi. org/10.1515/9781400821631.

Lijphart, A. (1999). Patterns of Democracy: Government Forms and Performance in Thirty-Six Countries. New Heaven: Yale University Press.

Lissidini, A. (1998). Una mirada crítica a la democracia directa: origen y las prácticas de los plebiscitos en Uruguay. Perfiles Latinoamericanos, 12, 169-200.

López Maya, M. (2014). Iglesia católica y democracia participativa y protagónica en Venezuela. Latin American Research Review, 49, 45-60.

Luna, J. (2008). Frente Amplio and the Crafting of a Social Democratic Alternative in Uruguay. Latin American Politics and Society, 49 (4), 1-30. 
McCoy, J. (2010). Venezuela under Chavez: Beyond liberalism. En C. Maxwell y E. Hershberg (eds). America's Left Turns: Politics, Policies and Trajectories of Change (pp. 81-100). Boulder: Lynne Rienner Publishers.

Moreira, C. (2004). Resistencia política y ciudadanía: plebiscitos y referéndums en el Uruguay de los '90. América Latina Hoy, 36, 17-45. Disponible en: https://doi.org/10.14201/ alh.7411.

Navarro, J. C. (1995). In Search of the Lost Pact: Consensus Lost in the 1980s and 1990s. En J. McCoy, A. Serbin y A. Stambouli (eds). Venezuelan Democracy Under Stress (pp. 13-31). United States: Transaction Publishers.

Negretto, G. (2012). Replacing and Amending Constitutions: The Logic of Constitutional Change in Latin América. Law and Society Review, 46 (4), 749-779. Disponible en: https://doi.org/10.1111/j.1540-5893.2012.00516.x.

Myers, D. (1995). Perceptions of a Stressed Democracy: Inevitable Decay or Foundation for Rebirth? En J. McCoy, A. Serbin y A. Stambouli (eds). Venezuelan Democracy Under Stress (pp. 107-137). United States: Transaction Publishers.

Observatorio del Proceso Constituyente de Chile. (2017). Historia del proceso constituyente chileno. Disponible en: www.redconstituyente.cl.

Philip, G. y Murillo, L. (2004). El Estado y el problema de la legitimación democrática en Venezuela bajo el sistema «Punto Fijo». Foro Internacional, 44 (1), 150-169.

Rilla, J. (2008). Uruguay 1985-2007: restauración, reforma, crisis y cambio electoral. Revista Nuestra América, 6, 95-63.

Sánchez, R. (2016). Venezuela (2015): un régimen híbrido en crisis. Revista de Ciencia Politica, 36 (1), 365-381. Disponible en: https://doi.org/10.4067/S0718-090X2016000100016.

Sanoja, P. (2009). Ideology, Institutions and Ideas: Explaining Political Change in Venezuela. Bulletin of Latin American Research, 28 (3), 394-410. Disponible en: https://doi. org/10.1111/j.1470-9856.2009.00309.x.

Schwartzberg, M. (2010). The arbitrarines of supermajority rules. Social Science Information, 49 (1), 61-82. Disponible en: https://doi.org/10.1177/0539018409354474.

Siavelis, P. (2006). Accommodating Informal Institutions and Chilean Democracy. En G. Helmke y S. Levitsky (eds.). Informal Institutions and Democracy: Lessons from Latin America (pp. 33-55). Baltimore: The John Hopkins University Press.

Viciano, R. y Martínez, R. (2000). Cambio político, cambio constitucional y la nueva configuración del sistema de partidos en Venezuela. Revista de Estudios Políticos, 110, 139-174.

Von Büllow, M. y Bidegaín, G. (2015). It Takes two to Tango: Students, Political Parties, and Protest in Chile (2005-2013). En P. Almeida y A. Cordero (eds.). Handbook of Social Movements across Latin America (pp. 179-194). Nueva York: Springer. Disponible en: https://doi.org/10.1007/978-94-017-9912-6_13. 